render the pupil to a greater extent mindful of his individual and personal wants and needs, must also be conceded; because he of all persons knows human wants and needs and suffering in a way that no other person does. It is he who well knows the importance of the strong and vigorous body, without which the mind must sooner or later give way, or become unbalanced and distorted.

A good physician in every public school in the land will, in one single generation, bestow on mankind a far richer heritage than the present system of teaching and the present method of doctoring. It is high time that the very worthy teacher and the capable physician should get together in our public schools, that the children of the land may suffer less, have less sickness and disease and death among their ranks, and have a training and discipline and an imparted knowledge vastly more suited to their individual and personal wants and relative environment. It is too much to ask or expect all of this at the hands of the teacher, who is of all people truly burdened. with tasks and required to teach pupils more than twice too much. It is neither necessary, nor does it educate, in the broader sense of the term. Who of us as grown, mature individuals does not know how trying it is on both the mind and the body to undertake to do too many things at once? What a strain and what, in many instances, are the results obtained? Usually not what one would wish.

The task to be performed must be measured by the capacity to do or perform; not only the mental effort, but the physical force or vigor necessary to support that effort. Again, I repeat, let us classify the pupils not only with reference to their mental aptitude, but also to the degree of health and physical vigor necessary to support that aptitude. This, then, I conclude, as I stated in the beginning of my short paper, is the prime basis for classifying pupils for purposes of instruction, and without this basis of classification there can be no progressive, as well as the most highly productive school work.

\section{TUBERCULOSIS IN COLORADO.}

METHODS OF DISSEMINATION AND MEASURES FOR ITS RESTRICTION.*

BY G. E. TYLER, M.D.

SECRETARY COLORADO STATE BOARD OF HEALTH. DENVER, COLO.

The records of the Denver Bureau of Health show the following mortality from tuberculosis:

\begin{tabular}{|c|c|c|c|c|c|c|}
\hline Gears $\ldots \ldots \ldots \ldots \ldots$ & 1893 & 1594 & 1895 & 1896 & 1897 & 189 \\
\hline Total dea & 43 & 377 & 428 & 368 & 489 & \\
\hline in as con- & 49 & 51 & 64 & 66 & 88 & \\
\hline er $\operatorname{cen}$ & 11.26 & 13.52 & 14.95 & 17.93 & 17.99 & 19. \\
\hline
\end{tabular}

This steady increase of the number of deaths from tuberculosis contracted within Colorado is sufficient to merit the earnest attention of all who are in any way interested in the prevention of the unnecessary spread of disease. At the August meeting of the Executive Committee of the State Board of Health, the secretary and Dr. J. N. Hall were authorized to seek a conference with the governor, the state dairy commissioner and the state veterinarian with a view to outlining a plan whereby the unnecessary spread of this disease might be restricted. An informal conference was held Sept. 26, 1899, and on Septeraber 30 , the two last named officials met with the executive committee for a full discussion of the problem.

*Read before the Denper and Arapahoe Medical Society, Dec. 26, 1899.
Owing to its far-reaching importance, and in order that there might be the largest possible collection of data, adjournment was had for three months and the parties to the conference were directed to obtain all information possible. The scope of the inquiry conducted by the State Board of Health has included all possible sources of in. fection known to sanitarians. For all practical purposes these sources of infection may be divided into three classes, as follows: 1. The expectoration of consumptives. 2. The milk from tuberculous cows. 3. The flesh of tuberculous animals. This does not mean that other sources may not exist, but no others of importance are known to exist. Of course it has been proven that tuberculosis is transmitted by heredity. But these cases are so rare that this possesses merely an academic interest; and it would doubtless augur better for sanitary control of this disease if people's minds were disabused of the idea that heredity is a factor of any importance in the actual transmission of the disease. Of course, too, the disease has been acquired by accidental inoculation, as during a surgical operation or an accidental cut at an autopsy. But so far as present knowledge goes the sanitarian is concerned with the three sources mentioned, and with no other.

Expectoration.- It is a fact so well established as to need no argument that the expectoration of consumptives contains the tubercle bacilli, and that these bacilli are the cause of the disease in others. It is also well established that so long as the expectoration is kept moist the tubercle bacilli are not distributed through the air; but so soon as it dries they are liberated and float in the air as fine particles too small to be observed, and that their inhalation with the breath causes the development of the disease in others. So long therefore as consumptives are allowed to spit on the streets the air is liable to contain these germs. So long as they are allowed to spit on the floors of street-cars or other cars, of halls and other public places, there is danger to the public. So long as they are allowed to spit on the floors of hotels or boarding-houses there is danger to the other occupants of these places. Moreover, the danger increases proportionately as the sunlight and fresh air decrease, so that the danger from indoor expectoration is considerably greater than from out-door spitting. It frequently happens that through ignorance, carelessness or feebleness the consumptive spits on bed linen, where the matter dries and becomes a source of danger. How frequent is it the practice to spit in the handkerchief all know. "The handkerchief dries quickly, and each time it is used the germ-laden dust infects the atmosphere. The question has been raised as to the relative degree of danger from expectoration in the different stages of the disease. Apparently some have considered the danger slight in the early stages, but great in the later periods where there is cavity formation and profuse expectoration. When it is considered that the earliest diagnostic method recommended to-day is the examination of the expectoration for the tubercle bacilli, and that they are frequently found before the physical examination reveals the presence of the disease, it will be seen that the earliest cases are sources of danger. When it is further considered that the cavity cases with abundant expectoration often show comparatively few tubercle bacilli, but do show immense numbers of the pus organisms, it will be concluded that the variation of danger in the different stages is not so great as at first supposed. An important question conconcerning the expectoration is: Who are liable to be endangered by carelessness in disposing of the sputum? 1 . The consumptive himself. It can hardly be doubted 
that many cases terminate fatally by reason of reinfection with the patient's own expectoration, and that these persons might have recovered had they been more careful in this regard. 2. All persons coming into more or less intimate association with the consumptive. The number of nurses, wives, and others who are constantly associated with consumptives who take the disease is not small. Cornet investigated the death-rate from consumption among certain religious orders devoted to nursing. "In a review of 38 cloisters, embracing the average number of 4025 residents, among 2099 deaths in the course of twenty-five years, 1320 (62.88 per cent.) were from tuberculosis." "The mortality in prisons has been shown by Baer to be four times as great as outside." (Osler.) It is notorious that the insane placed in asylums have a large death-rate from this disease. But in hospitals where due care is taken, as that at Falkenstein, the disease is rarely acquired, and indeed it is claimed that at that institution no nurse or attendant has ever taken the disease. 3. All persons, that is, the public generally, are to some degree endangered by the expectoration on the streets, in cars and other public places. Dr. W. C. Mitchell and the late Dr. H. C. Crouch absolutely demonstrated that the expectoration of consumptives continues to be a source of danger after at least thirty-five hours of exposure to direct sunlight. No one will question, therefore, that the expectoration has abundant opportunity to become thoroughly dry and to be wafted over a large area, thereby endangering, to some degree at least, the health and life of every citizen. 4. Animals are liable to contract the disease from the expectoration of human consumptives. The identity of animal and human tuberculosis, first announced by Koch, but often disputed since, has at last been demonstrated beyond the possibility of a doubt. The reasonableness of the proposition that animals may and do contract the disease from man is not therefore open to question. In a recent summary of Continental opinion on this subject Conn says: "So long as calves come in contact only with their mothers the amount of tuberculosis is very small; the amount of the disease, however, increases rapidly year after year; this increase in the disease is directly proportional to the contact with man. In sanitary institutes, where the attendants of the cattle are presumably in considerable measure suffering from tuberculosis the amount of tuberculosis among the cattle is always very great. There are practically no cases of healthy herds where they are attended by the patients of sanitary institutes. The condition of the herd may be always predicted from the condition of the family that has charge of the herd. If the inspector looks first at the people on the farm and finds one or two of them that appear to have traces of tuberculosis he can predict with absolute certainty that he will find the same disease among the cattle." Of interest in this connection is the fact that it is only in comparatively recent years that the existence of bovine tuberculosis in Colorado has been admitted. Though this is not the sole reason for the development of the disease among Colorado cattle it can hardly be doubted that the constant influx of consumptives to our state and their employment in attending cattle has had considerable influence.

Dairy Products.-That cows suffering from tuberculosis may give milk containing the tubercle bacilli is universally accepted among competent observers. Tubercle bacilli have repeatedly been found in such milk. Animals have been inoculated with the milk and died from typical tuberculosis. Other animals have been fed the milk of tuberculous cows and have succumbed to the dis- ease. Conn says: "It is the universal opinion in Europe, and in this country, of those who have looked into the matter that there is a danger to mankind in the use of tuberculous milk." Hirschberger states that an owner of a herd of cows known to be tuberculous withdrew the milk from market and used it without boiling to fatten his pigs. Almost without exception they became tuberculous and the entire stock had to be killed. Osler says: "There is no reason to believe that young children, or even adults, are less susceptible to the virus than calves or pigs, so that the danger of the disease from this source is real and serious. The great frequency of intestinal and mesenteric tuberculosis in children no doubt finds its explanation here. In Woodhead's analysis of 127 cases of fatal tuberculosis in children, the mesenteric glands were involved in 100." Dr. Martin, on behalf of the Royal Commission of England, experimented with milk from tubercular cows on guineapigs, rabbits and pigs. The milk from cows with tuberculosis of the internal organs but not of the udder produced no results. With that from cows with tuberculous udders every inoculation was positive. He then fed 27 animals with varying quantities of milk, and 19 developed tuberculosis. The abdominal organs were chiefly affected in those which developed the disease. Sometimes there was generalized tuberculosis ; sometimes the glands about the mouth and the angle of the jaw were affected. When the location of the disease is compared with the location of the disease in children who live largely on milk, the conclusion seems warranted that the infection in both cases is from a common source. In commenting on these experiments Dr. Martin says: "The milk of cows with tuberculosis of the udder possesses a virulence which can cuiy be described as extraordinary. In those cows where the tubercle bacilli were found in the milk, the feeding experiments were uniformly positive, as well as the inoculation experiments. It is noticeable, too, that a small dose of the milk diluted four times gave tuberculosis to all the animals fed, and that a dose of even .05 to .1 c.c. diluted with non-infected milk was sufficient to produce tuberculosis." A boarding-school in Paris had fourteen girls, nine of whom developed tuberculosis in a short time. It was discovered that they had all been using milk from one cow and that that cow was markedly tuberculous. (Conn.) A daughter of Dr. Goss, without hereditary taint or predisposition, was quite healthy up to the age of $1 \%$, when she sickened and died in about ten months. The autopsy showed extensive tuberculosis of the abdominal organs and mesenteric glands. Her father had been in the habit of taking her every week to a small farm which he owned, and her chief delight was to drink milk fresh from the cows. Four out of the herd of five cows proved tubercular and two had udder tuberculosis. No other source of infection was discovered. (Kilpatrick). Mayo says, and he speaks from the standpoint of the veterinarian: "As tuberculosis of cattle is identical with that of man, and the disease can be transmitted to mankind through the milk and flesh, which furnish so large a part of the food of man, the importance of this disease is apparent." The entire subject of milk infection was taken up by the Massachusetts Society for the Promotion of Agriculture, the results of the studies of Professor Ernst being published by this society. He found that tubercle bacilli sometimes occur in the milk of cows having no demonstrable tuberculous lesion of the udder. This was determined by cover-glass preparations, as well as by inoculations of animals. Further, it was found that the feeding of infected milk to animals 
caused the disease in a certain proportion of cases. Ernst came to the following definite conclusions: 1 . While the transmission of tuberculosis by milk is probably not the most important means by which the disease is propagated, it is something to be guarded against most carefully. 2. The possibility of milk from tuberculous udders containing the infectious element is undeniable. 3 . With the evidence here presented, it is equally undeniable that milk from diseased cows with no appreciable lesion of the udder may, and not infrequently does, contain the bacillus of the disease. 4. Therefore, all such milk should be condemned for food. Bay examined 351 separate specimens of cows' milk by centrifugation, and in 51 found tubercle bacilli.

There are those who assert that the danger to the public health from such sources is so slight as to be of no practical importance. Those making this statement are frequently directly or indirectly connected with dairy work. But if their argument is sound it should be accepted. It may be well, therefore, to examine their chief statements. They assert that unless there be general tuberculosis or udder tuberculosis there is probably no danger. They make the further statement that dairymen will of themselves, without supervision, separate a cow suffering from general tuberculosis from the milkproducing herd. What assurance has the public that this will be done voluntarily? Granting that many dairymen will do it, the public demands, and has a right to demand, that such separation shall not depend on the volition of a dairyman. In view of the fact also that here in Colorado dairymen have had to be forced to separate cows with notorious evidence of tuberculosis, the statement seems too insignificant for further attention. This is not saying, however, that many would not do this; but $I$ do contend that the dairymen as a class could not be depended on to do it. It is also true that there may be widespread bovine tuberculosis without sufficient symptoms to excite suspicion. N. S. Mayo, M.S., D.V.M., says: "It is astonishing how badly an animal may be diseased and to all appearance be in good health. Several years ago I was called to treat a purebred Shorthorn cow that, until the day I was called, had appeared in excellent health. The disease was diagnosed as tuberculosis and she was destroyed. Post-mortem examination showed both lungs badly diseased, a tuberculous abscess in one lung containing a pint of pus. Her heart was a mass of tuberculous tissue, weighing 16.5 pounds, and almost every internal organ more or less diseased. This cow had a sucking calf two months old at her side. The calf was destroyed, and was found to have a tuberculous abscess in one lung as large as a walnut, and the bronchial lymphatic glands were also diseased." In view of the difficulty of diagnosis, and in view also of the findings of Professor Ernst, above quoted, and of the further fact that no one can say at what moment a cow suffering from a local tuberculosis may develop a general one or udder tuberculosis, it is certainly an irrational procedure to allow the sale of milk from a cow with a local affection of this nature. It is also worthy of note that the very persons who minimize the danger to human beings from such milk, emphasize the fact that this milk should be Pasteurized or sterilized before feeding it to calves or pigs. One more argument used seems to demand notice: Some assert that during the past forty years bovine tuberculosis has greatly increased, while during the same time human tuberculosis has decreased, and this in spite of the fact that there has been a considerable increase in the use of dairy products. If the truth of these assertions should be granted the conclusion does not follow that there is little or no danger from milk. For far greater attention has been paid during this period to the prevention of infection in other ways than ever before. But Sir Richard Thorne, medical adviser to the Local Government Board, London, said, on Nov. 9, 1898, that the increase of tuberculosis had gone hand in hand with a steady increase in the consumption of cows' milk as a food, English people being habitual consumers of uncooked milk. In Iceland, which is without cows, human tuberculosis is unknown. Japan was free from tuberculosis until cows were introduced from America. Since that time the disease has rapidly developed until now nearly one-third of all deaths are due to this disease.

It is established beyond cavil that milk is a sufficient source of danger to demand the earnest attention of health officials. There appears to be no reason for not accepting without question the doctrine of the danger of milk from tuberculous cows.

Meat._-"There has been a large amount of investigation in connection with the possibility and the probability of tuberculosis being carried from animal to man in the flesh of the animal used as food. A very large amount of experiment in this connection has been carried on in the last fifteen years. These experiments have in large degree consisted in feeding tuberculous flesh to animals known to be subject to the disease, and then noticing whether its consumption produces tuberculosis in the animals thus fed. The result of these experiments has been conclusive enough. While it does not always happen that tuberculosis will follow the eating of tuberculous material. by such animals, it has resulted in a sufficient number of cases to show beyond peradventure that this disease may be transmitted by the flesh of animals suffering from the disease." (Conn.) It is interesting to note that in New York City, for six years, the average annual death-rate from tuberculosis per 100,000, among the Russian Polish Jews, was but 76.72 , while for the remainder of the population it was 427.75 . When their scrupulous care as to meat inspection is considered, one can not help wondering if this may not have some effect in producing this wonderful relative freedom from the disease. The almost unanimous opinion concerning the danger from meat is that if there is general tuberculosis the entire carcass is unfit for food. But if the disease be localized the affected part is all that need be condemned. Thorough cooking kills the germ, but so much beef is eaten rare that anything less than the above plan indicates is unsafe.

What evidence is there of bovine tuberculosis in Colorado? It appears to be the general opinion of observers that little, if any, exists among range cattle. This is not strange in view of the continuous out-of-door life which cattle of this class lead. Tuberculosis bears a rather close ratio to the indoor life and forced feeding of cattle. Yet Dr. Hillkowitz and I witnessed the slaughter of a cow from the range, one that had never been outside of Colorado, which had a beginning pulmonary tuberculosis. As to the disease among dairy cows, no one who has investigated the matter will contend that it does not exist. The Denver Bureau of Health has made promiscuous tests, as follows: In 1897, $47 \%$ tests, 10 condemned, about $21 / 10$ per cent; in 1898, 4 tests, 1 condemned, 25 per cent.; in 1899, 101 tests, 6 condemned, about 6 per cent.; total number of tests 582 , total condemned 17; per cent. condemned, about 3. Dr. Hillkowitz, in his interviews with Hebrew slaughterers, found that not one of them would knowingly buy a dairy cow for slaughter because of the known prevalence of 
tuberculosis among this class. At a certain Denver slaughter-house, notorious for bad cattle, one of the butchers told me he thought 90 per cent. of all dairy cows slaughtered there were tuberculous. No butcher interviewed, and they have been at random, has put the percentage lower than 30 . A prominent one who tries to buy the best beeves told me he would not knowingly buy dairy cows, but said that in spite of all care he is compelled to reject a considerable number of carcasses.

There are practically but two methods of determining the presence of tuberculosis among cattle, viz., post-mortem inspection and the tuberculin test. The symptoms are so latent and obscure and the physical signs are so uncertain by reason of the thick chest walls of the animal that the disease may advance extensively before it is suspected. As yet there has been no adequate and systematic slaughter-house inspection in Colorado. The other duties of the city meat inspectors prevent their giving much attention to this matter, so there are no data at hand from which absolutely to determine the per cent. of tuberculous animals coming to slaughter. The State Board of Health has tried to obtain the estimate of the butchers without bias, and this opinion is recorded above. Every one knows that no adequate testing with tuberculin has been made, but the available statistics are quoted above. To hazard a statement of the amount of bovine tuberculosis in Colorado would therefore be unwise. But it can be asserted with positiveness that the disease exists. It is also probably true that a complete testing of all dairy cows within the state would reveal a larger prevalence than has been supposed. Certainly it is true that unless measures are taken to lessen its spread the percentage will increase rather than otherwise.

This introduces an idea which has not received sufficient consideration, but which, nevertheless, is exceedingly important, i. e., that the prevention of bovine tubereulosis is of marked importance to the dairymen and stockmen themselves. Tuberculosis enters a herd in the first instance from without, by one of the methods above mentioned. Once it has entered, its spread is certain under ordinary conditions. 'This means a prospective loss of a percentage at least of the stock and the continual infection of fresh animals. Instances are recorded where owners have been forced to entirely restock their farms because of the continual spread of the disease. Conn says: "The statistics being collected in the last few years are tending to show that bovine tuberculosis is not only on the increase but on the very rapid increase. Twenty-five years ago the amount of tuberculosis reported from slaughter-house inspection was only 3 to 5 per cent. To-day it is 10 to 50 per cent., and more often approaching the higher than the lower figures."

In Germany, in 1895, there was a direct loss to the farmers of $\$ 1,500,000$ from the condemnation of carcasses of slaughtered cattle alone. It should be remembered, too, that German inspection does not condemn every tuberculous carcass, so that this represents but a small part of the money value of the tuberculous animals. Though it is probably true that our percentage is lower, the danger is present, and it is far more economical to attack the problem now than it will be if a few years are allowed to pass in inaction. Therefore, the dairymen and all breeders of stock should welcome rather than oppose a practical move in this direction.

How can the milk supply be protected? Not by examining the milk for the tubercle bacilli, because milk from a tuberculous udder may be free to-day and full of bacilli to-morrow, and to analyze every milking is a physical im- possibility. Not by mere inspection of the herd. Though this would reject the majority of animals with advanced general tuberculosis and those with pronounced udder disease; there are real dangers, according to the statements of competent authorities-e. g., Mayo and Ernst -from animals in which the disease can not be discovered by even close inspection. There remains but one known method, the use of the tuberculin test and the prohibition of the sale of milk from every animal not shown free from reaction. The simplicity of the test makes it easy of application. Its absolute freedom from danger is now acknowledged. Its accuracy may be understood from the following figures given by Mayo: Out of 11,313 cattle tested, 5,73\% reacted. On post-mortem, 5,746 were found tubercular. Two reacted that did not show tuberculosis and 9 did not react, but were tuberculous. This shows an average of but one error in every 1,028 tests.

This testing should be done by officials only, in order to be sure of its accuracy and to guard against fraudulent certificates. The method is simple, but takes time. The tester takes the temperature of the animals every two hours, from 6 a. m. to 8 p. m., and records this as a basis for comparison. At 10 p. m. he injects 2 c.c. of tuberculin (B. A. I.) hypodermically. Beginning at 6 a. m. of the following day he records the two-hourly temperature until $10 \mathrm{p}$. m. If. the temperature rises $2 \mathrm{~F}$. or more above the corresponding temperature of the day before, the animal is considered tuberculous.

What shall be done when tuberculosis is discovered in a herd? 1. The reacting animals should be separated absolutely from the non-reacting, without delay, and there should thereafter be absolutely no communication of the herds, as by using the same feeding places, watering troughs, etc. The reacting animals should be marked with an imperishable mark or brand. 2. The barn which they have occupied should be completely disinfected. 3 . The sale of milk from the reacting herd should be stopped at once. 4. It is not necessary to order the slaughter of every reacting animal. If a man has but one or two reacting animals he will probably prefer to kill them. But even then he need not suffer great financial loss. For unless there is general tuberculosis he should be allowed to fatten the animal for beef, if he will consent to slaughter under competent inspection. But if he has a considerable number of reacting animals he probably will wish for some other solution of the problem. If he can and will absolutely separate and keep separate the two herds, and if he will separate the calves of the reacting herd, have them tested and bring them up on non-infected milk, there is no reason why he should not be allowed to use these diseased animals to build up a healthy herd. But this latter plan depends for its success on rigid observance of the conditions mentioned.

The two greatest hindrances to the solution of this problem have been the objection, on the part of the owners, to the financial loss involved in compelling the slaughter of their animals without compensation, and that on the part of the state to the enormous burden involved in compensation. With these two objections removed there should be active, earnest co-operation of all concerned. I believe the two plans presented do away with the objections, for the farmer will be able to sell many diseased animals, getting good compensation therefor, and where his herd has become largely invaded he can, by proper care, build up a healthy one and be assisted in doing so. He must lose only those animals which would soon die. On the other hand, the state does not need to spend a great amount of money for condemned animals. I am 
thoroughly convinced that it will pay the owners to take up this problem and pay the necessary expenses of testing if some competent authority will guarantee the accuracy of the work. But it is doubtful if they will without some encouragement.

The question now confronting us is: What shall we do to lessen the spread of this disease among animals and mankind?

1. The continual education of the public is essential to success. Every person should be informed as to preventive measures. I therefore recommend that a carefully worded circular suitable for popular distribution be prepared by the State Board of Health, and that an effort be made through local health officers, physicians, libraries and schools to put this circular in the hands of every resident of Colorado. This circular should set forth the dangers from expectoration and from milk and meat supply, and the measures necessary to prevent the danger.

2. Public expectoration should be lessened by proper placards and be prohibited by ordinances in the larger places of the state. Women's clubs, city improvement societies and the public press will be of great aid and I recommend that their active co-operation be secured where possible.

3. I recommend that all rooms where deaths from consumption are reported be disinfected immediately by the local health officers.

4. All insane asylums, prisons, reformatories and hospitals should be required to keep tubercular and nontubercular inmates separate. For state institutions this is the work of the State Board of Health; for others it is the work of local boards of health.

5. So far as possible dairymen should be persuaded to have their herds tested and use this as a means of advertising. But as this is insufficient, I recommend that by the promulgation of health regulations or by the passage of ordinances where necessary, dairymen be compelled to produce official certificates of freedom from tuberculosis before they are granted permits to sell milk. Due notice must be given, but this ordinance can go into effect by July 1, 1900, if the matter is properly pushed, and I recommend that date. Where necessary it will be well to compel the payment of a certain sum per head for every cow in the milk-producing herd, and to utilize this fund for testing and sanitary supervision. The State Board of Health is willing to select competent men for this work on request of local officers, and to frame and publish rules governing such testing and inspection; in short, to facilitate the work in every way. It seems to me desirable to have an agreement between the local boards and the State Board of Health, so that no inspector will be employed without authority from the latter. Uniformity of regulations and complete records of the work can thus be secured, and no confusion as to conflict of authority can arise.

6. I also recommend that the employment of tubercular persons on dairy farms or at milk depots be absolutely prohibited, by ordinance.

7. Ordinances should be passed prohibiting private slaughter-houses and requiring that all animals be slaughtered at public abattoirs under competent inspection. If federal meat inspection can be secured, all condemned meat should be destroyed in order to prevent its being placed on the local markets. If federal inspection can not be secured, a tax should be levied on the slaughter business sufficient to meet the expenses of inspection.

8. I further recommend that the active aid of the pub- lic press be enlisted in furthering all phases of this important work.

'These measures were definitely agreed on at a conference of state and local officials held on Dec. 23, 1899, and will be carried out by the responsible officers.

\section{REGULATION OF THE PRACTICE OF MEDICINE.* \\ BY JUDGE JOHN I. DILLE. \\ DEAN OF HIGHLAND PARK COLLEGE OF LAW. DES MOINES, IOWA.}

The power and the duty of the states to regulate the practice of medicine have been fully established. It is the inalienable right and imperative duty of the government, by legislation, to promote the health, morals, education and good order of the people. This right, vested in the people in their sovereign capacity, has been likened to the individual right of self-defense, the exercise of which is a part of the law of self-preservation. The police is a plenary power, and may be exercised by the state to regulate or prohibit things inconsistent with the public welfare.

No other function. of government has been so frequently appealed to, nor so successfully exercised, and none other is of greater importance to the people, individually and collectively. We look to this power for the suppression and punishment of crime, the preservation of public peace, the regulation of dangerous employments, the sale and use of dangerous commodities, the prohibition of acts inconsistent with public morals, the protection of the weak from the aggression of the strong, the ignorant and unwary from the power of the cunning and the unscrupulous, and for the maintenance of the public health.

It is by virtue of this power that the state maintains prisons, confines lunatics, regulates the conduct of vagrants, establishes fire limits, regulates the use of dangerous machinery and public conveyances, forbids lotteries and gambling, prescribes quarantine regulations, prohibits adulteration of foods, controls the liquor traffic; in short, it is the weapon to battle with all of the evils of society.

It is under this classification that the state regulates trades, occupations and professions, notably those of plumbers, engineers, pilots, masters of ships, telegraph operators, druggists pharmacists, lawyers and physicians.

Some physicians question the propriety of such legislation. It is urged that the ignorant are inclined to look on such legislation as an attempt by the physicians in practice, to monopolize the business, and that under defective or poorly-executed laws the dishonest and incompetent succeed in getting certificates to practice, and their pretensions are made respectable thereby. $\mathrm{My}_{\mathrm{y}}$ judgment is that the united efforts of the profession could not effect a repeal of the legislation on this subject. The necessity for such legislation is firmly fixed in the minds of most intelligent laymen, as the legislation on the subject in nearly every state in the Union from the earliest period to the present time shows. It would seem to be your duty to the public to assist in formulating such legislation and in making the same effective. The man of science can hardly afford to shrink from public dutybecause its discharge is unpleasant, nor because some of the beneficiaries are incapable of appreciating the protection afforded by his efforts. The self-consciousness of public duty well performed, and the approbation of

* Delivered before the Polk Connty Medical Society, Oct. 2, 1899 